\title{
A escalada dos imperadores proscritos: Estado, conflito e usurpação na Antiguidade Tardia (285-395)
}

The rise of the outcast emperors: State, conflict, and usurpation in Late Antiquity (285-395)

SILVA, Gilvan Ventura da. A escalada dos imperadores proscritos:

Estado, conflito e usurpação na Antiguidade Tardia (285-395).

Vitória: GM Editora, 2018. 166 p.

\section{Larissa Rodrigues Sathler*}

Recebido em: 15 maio 2021

Aprovado em: 30 maio 2021

esultado da pesquisa de mestrado do professor da Universidade Federal do Espírito
Santo, Gilvan Ventura da Silva, a obra A escalada dos imperadores proscritos: Estado,
conflito e usurpação na Antiguidade Tardia (285-395) foi desenvolvida no início da década de 1990 e publicada pela primeira vez em forma de livro no ano de 2018.

Apesar do extenso intervalo entre a defesa e a publicação, a produção ainda conserva seu lugar no conjunto da literatura do assunto em questão, visto que oferece ao leitor um trabalho bastante proveitoso e atual sobre as usurpações na época tardia, tema que ainda carece de publicações em língua portuguesa. Além disso, se comparada à ampla bibliografia estrangeira que, nas últimas três décadas, vem analisando as usurpações na Antiguidade Tardia de maneira mais pontual e menos coletiva (SILVA, 2018, p. 16), a obra de Silva ocupa uma posição ímpar no centro deste debate, não apenas por já haver respondido algumas questões levantadas em trabalhos relevantes, como o de Sandra Seibel (2004) e o de Joachim Szidat (2010), publicados mais de dez anos depois de sua produção, mas também por contribuir para o preenchimento de uma lacuna no que diz respeito à análise do tema de forma coletiva, visto que apresenta uma interpretação estrutural e sistêmica das usurpações que ocorreram no Império tardio.

* Mestra pelo Programa de Pós-Graduação em História da Universidade Federal do Espírito Santo. 
O livro se encontra dividido em cinco capítulos, a saber: "O enfoque sistêmico e a História Política"; "O Dominato entre a memória e a História"; "A Reparatio Saeculi"; "As usurpações e os seus protagonistas"; e "A reação imperial". No primeiro capítulo, a adoção do enfoque sistêmico foi uma escolha certeira, pois nos permite observar a organicidade dos acontecimentos em torno das usurpações. Nesse caso, o sistema político romano é apresentado como um sistema de caráter adaptativo complexo, pois atuava em prol de conservar a sua estrutura em face às constantes ameaças de usurpações e de reelaborar-se continuamente a fim de alcançar a estabilidade necessária para se prolongar no tempo. Além disso, a partir da Teoria de Sistemas o autor torna possível ao leitor perceber o conflito como um desvio inerente ao próprio sistema e não algo que vem do exterior e introduz a desordem. Nessa lógica, os conflitos, leiam-se as usurpações, são estruturalmente provocados e mantidos pelos próprios representantes da ordem social que, por sua vez, definem e realimentam as regras de normalização. Quanto à escolha do campo de investigação, a análise das usurpações produzidas entre os anos de 285 e 395 não caberia melhor em outra especialidade do conhecimento histórico do que na História Política, visto a sua capacidade de captar uma perspectiva temporal mais abrangente, com destaque para os acontecimentos recorrentes.

No segundo capítulo, o autor preocupa-se em iluminar alguns lugares de memória presentes na historiografia sobre a fase final do Império Romano. Para tanto, apresenta um repertório de concepções historiográficas que acredita serem insatisfatórias para a compreensão das relações de poder próprias da Antiguidade Tardia, a saber: o mito do Estado como uma instituição onipotente a partir do século III; o mito da decadência do Império Romano do Ocidente; a brutal antinomia entre o Estado e a sociedade; e as usurpações como um epifenômeno.

No terceiro capítulo, Silva investiga como o Estado romano, repartido em seus diversos subsistemas, foi reorganizado a partir de Diocleciano. Assim, nos informa que, na transição do século III para o IV, o Estado romano modificou-se com base em três objetivos essenciais: a conclusão do processo de centralização política; a manutenção de um aparato militar sensivelmente ampliado; e a reafirmação da autoridade imperial em todo o orbis romanorum a fim de evitar o excesso de sedições próprios da Anarquia Militar. Quanto aos seus subsistemas, o autor nos informa que coube ao comitatus definir todas as ações necessárias para realizar estes três objetivos. Já ao subsistema administrativo, captar recursos para as tropas e tornar mais efetiva a presença do imperador ao lado dos súditos; e, por fim, ao sistema coercitivo-militar coube a segurança de todo o Império. Junto a todos estes subsistemas, mais especificamente no vértice de todo o sistema político romano, se encontrava o dominus, governante supremo que, por meio de um 
aparato ideológico, passou a ser percebido pelos súditos como o restituidor da felicidade e da paz dentro do Império.

Nos capítulos quatro e cinco, o autor adentra as investigações acerca das usurpações propriamente e nos permite conhecer o quanto o Estado da época tardia foi capaz de gerenciar com precisão esse tipo específico de conflito. Para isso, ele nos apresenta um total de vinte e duas usurpações que ocorreram entre os anos de 285 e 395. Para efeitos de melhor compreensão do que deseja tratar, o autor teve ainda o cuidado de situar tais usurpações no tempo, agrupando-as em quatro ciclos: o Ciclo da Formação da Tetrarquia; o Ciclo da Crise da Tetrarquia; o Ciclo do Governo de Constâncio II; e o Ciclo da Dinastia Valentiniana.

Outra informação importante para a compreensão desses movimentos dentro da estrutura política do Estado na Antiguidade Tardia é o fato de que, para o autor, o conceito correto para identificá-los não seria "usurpações", uma vez que os "usurpadores" não devem ser examinados como anti-imperadores ou imperadores ilegítimos, mas tão somente como imperadores proscritos, pois foram reconhecidos como Augustos por uma parcela da sociedade e não se mantiveram no poder por conta das retaliações aplicadas pelos representantes da ordem estabelecida. Logo, o termo usurpação foi utilizado na obra por mera conveniência e sem qualquer sentido pejorativo (SILVA, 2018, p. 100).

De modo geral, ao invés de analisar as usurpações nas suas singularidades, Silva mostrou como elas representaram um elemento importante para a transformação e consolidação do sistema político romano na Antiguidade Tardia. Nesse caso, as usurpações não apenas contribuíram para a formação e falência da Tetrarquia, sistema no qual vemos acontecer a "partilha da autoridade imperial", mas também consistiram em movimentos organizados e ordenados por usurpadores que recorreram à própria estrutura político-administrativa do Império, da qual eram integrantes como funcionários da administração civil, do exército ou, em menor caso, de nenhum dos dois, apenas como cidadãos. Em suma, os usurpadores pertenciam ao "bloco de poder" e, devido à liderança que exerciam, tinham capacidade para arregimentar recursos sob a forma de homens, víveres e numerário a fim de viabilizar os golpes militares que os fizeram imperadores.

Além de analisar a origem social dos imperadores proscritos, o autor também se propôs a investigar os grupos sociais que os apoiaram. Como qualquer outro conflito social que apresenta um mínimo de organização, para que as usurpações acontecessem, era preciso contar com a colaboração de grupos sociais, isto é, de um agregado de pessoas que compartilham um sentimento de pertencer conjuntamente e de interesses semelhantes (SILVA, 2018, p. 110). Nesse caso, o autor afirma que somente o exército é plenamente identificável como grupo, já que somente os militares, incluindo os seus 
titulares, preencheriam todos os requisitos para a formação de um grupo de conflito nas sociedades agrárias, principalmente no que se refere à comunicação entre seus membros. Assim, pilar das usurpações romanas, o exército é o único grupo que ameaça o monopólio da autoridade estatal, lembrando que a própria concessão do título de Augusto é, na época tardia, prerrogativa dos militares. Contudo, para Silva, não podemos ignorar o fato de que os usurpadores, para se fortalecerem, não se restringiram às forças militares e buscaram apoio em outros segmentos sociais, a saber: as milícias paramilitares; a plebe da cidade e seus administradores; os decuriões; os comerciantes; os senadores; os camponeses, ainda que em menor grau; e a cidade e seus habitantes, elementos importantes para a constituição da usurpação e do processo de legitimação imperial.

A respeito destes segmentos, o autor nos informa que eles eram peças importantes para confirmarem o direito à púrpura por parte do usurpador. As cidades, em especial, formavam "as células da administração imperial, cabendo aos seus líderes, os decuriões, a arrecadação dos impostos" que seriam transformados em provimentos para a execução do golpe. Além disso, as cidades da Antiguidade Tardia eram "autênticas praças fortes cercadas de muralhas", o que poderia facilitar a progressão dos imperadores em tomar o partido do imperador legítimo. Por fim, obter o reconhecimento das cidades e seus habitantes ampliaria imensamente a legitimidade da usurpação, pois eram nelas que "os agentes da administração pública atuavam, de modo que sem a base urbana seria praticamente impossível aos usurpadores se manterem" (SILVA, 2018, p. 113-14).

De mais a mais, na obra são analisados quais motivos levaram os usurpadores e seus apoiadores a se lançarem contra a ordem estabelecida; o modus operandi adotados pelos usurpadores no processo de sua entronização; e, por último, a reação imperial às usurpações. Sobre os motivos que levaram os usurpadores a conflitarem com as autoridades instituídas, Silva (2018, p. 114-15) afirma que, em termos globais, todas as usurpações tinham o intuito de reverter determinado padrão de distribuição da autoridade dentro do aparelho estatal. Ou seja, na medida em que se tem um "bloco de poder", nem todos que dele participam compartilham de um mesmo grau de autoridade, o que é capaz de gerar conflito entre os seus membros caso aqueles que ocupam uma posição secundária resolvam que é a hora de mudar as regras estabelecidas, não se importando se isso acarretaria ou não em sua exclusão do bloco. Decerto, esse motivo, que é tido como subjacente pelo autor, precisaria se alinhar aos interesses manifestos dos próprios titulares da usurpação, bem como dos segmentos sociais que os apoiavam, no caso, o exército, a plebe urbana e os decuriões. Assim, três são os motivos manifestos dos usurpadores, elencados pelo autor: 1) aqueles que, dada as condições de política do Império veem a sua posição dentro do Estado se tornar insustentável e, por isso, recorrem 
à usurpação como uma forma de escapar de um risco; 2) aqueles que, por conta do padrão de distribuição da autoridade, não são ameaçados diretamente por fazerem parte desse padrão, mas se sentem desprestigiados ou privados de algo que deveria lhes pertencer por direito; 3) aqueles que, visando a impedir o golpe aplicado por outro usurpadores, acabaram por se fazer um imperador proscrito também (SILVA, 2018, p. 115).

O interesse dos apoiadores na ascensão do usurpador também era imprescindível, fato revelado, por Silva, ao constatar que todos os golpes resultantes na proclamação de um novo imperador somente foram possíveis em virtude da insatisfação da sociedade em relação à ação governamental em curso. Em outros termos, o que se tem é uma situação de insatisfação latente contra o governo, na qual o usurpador emerge como um catalisador das aspirações sociais, tornando-se o único capaz de solucionar os problemas vividos pelos segmentos que se sentem de alguma forma prejudicados.

Uma vez instaurado o golpe, e contando com uma base de apoio para se manter no poder, os imperadores proscritos seguiam para o processo de entronização. Para tanto, adotavam o modus operandi dos imperadores legítimos e se apresentavam às tropas reunidas para a obtenção dos títulos de imperator e Augustus. Tendo sido aclamado pelas tropas, o imperador passava a exigir dos seus soldados a devotio, isto é, a dedicação integral de seus corpos e de sua vontade ao dominus expressa por meio de um juramento de perpétua fidelidade chamado sacramentum. Ao lado da devotio, o soberano revestiase dos símbolos visíveis de sua autoridade. A saber: o paludamentum, longo manto de púrpura reservado ao imperador; o diadema (infula), símbolo da divinização importado das monarquias helenísticas; e os sapatos decorados com pedras preciosas, símbolos que representavam o brilho que deveria acompanhar o imperador, personificação da luz de Roma. Soma-se a estes símbolos o rito da adoratio, adoração de joelhos e o beijo na barra do manto do imperador, que tinha o poder de assemelhar o dominus a uma entidade mística facilmente identificada com os deuses. Por fim, da mesma forma que os governantes legítimos deveriam distribuir benefícios aos seus súditos, os usurpadores aclamados deveriam expressar a sua capacidade material de distribuir donativas caso quisessem conquistar o apoio do exército (SILVA, 2018, p. 124-25).

Após reproduzir de forma mais idêntica possível todo o cerimonial de entronização dos imperadores legítimos, para não correrem o risco de serem rejeitados pelos habitantes da cidade, os usurpadores precisavam tornar público o acontecido a fim de obterem aprovação, apoio e submissão. Segundo o autor, para executarem essa tarefa, os usurpadores se valeram de três veículos de propaganda na Antiguidade Tardia: as imagens sob a forma de estátua ou retrato, as epístolas e as moedas. As imagens eram um poderoso agente de centralização, pois se encontravam em vários ambientes onde a autoridade do 
imperador era exercida. Já por intermédio das epístolas, os usurpadores poderiam não apenas explicar às cidades, aos altos funcionários da administração pública e aos diversos destacamentos militares as condições nas quais foi aclamado imperador, mas também poderia exortá-los a segui-los e prometer melhores condições para o Império. Quanto às moedas, não há dúvida de que estas eram símbolos nítidos de soberania. Como afirma o autor, elas serviam tanto como um poderoso agente de propaganda por conta do seu uso corrente quanto como símbolos exclusivos da autoridade imperial.

Na seção final da obra, é abordado como se deu a reação imperial às usurpações. De acordo com o autor, a monarquia romana, excludente por excelência, jamais poderia aceitar passivamente o compartilhamento do poder com indivíduos que se fizeram imperadores por si só, sem respeitar as ordens de sucessão ditadas pela casa imperial. Dessa forma, dois padrões de comportamentos foram tomados mediante o problema: o diálogo e a repressão.

Estas duas formas de comportamento variaram de acordo com a conjuntura política vigente. Por vezes, a autoridade imperial, mesmo que a contragosto, julgou mais prudente manter o diálogo e reconhecer os imperadores rivais. Assim, ora aceitaram os usurpadores por um breve período e depois os erradicaram do sistema e ora absorveram e assimilaram os usurpadores ao sistema. Para o autor, essa assimilação não foi algo fortuito, mas sim o resultado da impotência do Estado em arregimentar recurso materiais e ideológicos para detê-los e da própria organização interna do movimento, que desencorajava qualquer ação efetiva contra os usurpadores (SILVA, 2018, p. 133). No que se refere à repressão, Silva nos informa que este é o padrão de gerenciamento de conflitos predominante para as usurpações. Na medida em que o sistema político do Estado era ameaçado, a tendência maior dos imperadores legítimos não era manter o diálogo, mas sim eliminar os focos dissidentes mediante o uso ostensivo da força militar.

Todas as usurpações que não foram reconhecidas e assimiladas pelo sistema resultaram em guerra civil com intensas demonstrações de violência dos dois lados, o que nos fornece não apenas uma boa medida de como os grupos rivais estavam empenhados em defender sua causa, mas também é um indicativo de que o Estado não estava conseguindo administrar de forma conveniente as demandas sociais presentes no Império. Para Silva, a gravidade do ato requeria dos imperadores legítimos uma reação que eliminasse os adversários para evitar a consecutividade do conflito. Assim, todos os réus acusados de alta traição estavam sujeitos à pena capital, e aqui lhes era negado qualquer direito de defesa, além do confisco de seus patrimônios.

Concluída a repressão física e pecuniária contra os imperadores proscritos, os imperadores legítimos também precisavam empreender uma repressão ideológica com 
o propósito de excluir as ações dos golpistas da memória da sociedade. Para tanto, se valeram da damnatio memoriae, uma tradição que, na época da Antiguidade Tardia, foi usada de forma intensa contra os usurpadores e consistia na destruição das suas efígies e na revogação de seus atos de governo. Salvo o uso da damnatio memoriae, o autor nos informa ainda que os representantes da ordem legítima recorreram, de forma semelhante aos seus rivais, ao apoio do exército, da plebe urbana e da ordem dos decuriões. Além disso, também fizeram uso da propaganda para atacar as imagens dos usurpadores apontando pari passu a gravidade do crime que estes últimos perpetuaram contra a ordem estabelecida e os gloriosos feitos da casa imperial ao suprimirem os adversários da orbis romanorum.

A partir do que foi apresentado, A escalada dos imperadores proscritos: Estado, conflito e usurpação na Antiguidade Tardia (285-395) pode ser considerada uma obra cuja inovação é apresentar as usurpações como um vetor muito importante para condicionar as transformações experimentadas pelo Dominato. Desviando-se dos correntes estudos que analisam as usurpações em suas singularidades, o autor demonstra com maestria que as usurpações seguiram um modus operandi em comum e, embora desestabilizassem a ordem constituída, os imperadores proscritos não pretenderam de modo algum contestar a legitimidade do sistema, mas sim integrar o colégio imperial. Nesse caso, em nenhuma delas se encontra uma proposta de redefinição do sistema político e, por isso, as usurpações não poderiam ser apontadas como responsáveis diretas da desintegração do sistema político romano durante a época tardia. Ao invés disso, em uma hipótese mais convincente, as usurpações devem ser lidas como conflitos agregadores, isto é, como conflitos que, quando superados, permitem ao sistema readaptar-se no sentido da autoperpetuação.

Por fim, reiteramos que a obra apresenta uma valiosa contribuição para os pesquisadores que se propõem a investigar os conflitos político-sociais que irromperam no Império Romano tardio. De leitura instigante, esta é uma obra que, além de apresentar aos leitores um cuidadoso tratamento metodológico e teórico, passadas décadas da sua produção, ainda detém argumentos históricos convincentes e bastante atuais, o que a torna ainda mais apreciável.

\section{Referências}

SEIBEL, S. Typologische Untersuchungen zu den Usurpationem de Spätantike. 2004. Tese (Doutorado em Humanidades) - Programa de Pós-Graduação em Humanidades da Univesität Duisburg-Essen, 2004. 
SILVA, E. C. M. da. Prefácio. In: SILVA, G. V. da. A escalada dos imperadores proscritos: Estado, conflito e usurpação na Antiguidade Tardia (285-395). Vitória: GM Editora, 2018, p. 11-24.

SILVA, G. V. da. A escalada dos imperadores proscritos: Estado, conflito e usurpação na Antiguidade Tardia (285-395). Vitória: GM Editora, 2018.

SZIDAT, J. Usurper tanti nominis: Kaiser Und Usurpator in der Spätantike (337-476 Chr.). Stuttgart: Steiner, 2010. 